\title{
Consumers' Abductive Inference Error as Cognitive Impairment
}

\author{
Woong-Hee HAN ${ }^{1}$
}

Received: March 12, 2020 Revised: May 24, 2020 Accepted: June 10, 2020

\begin{abstract}
This study examines cognitive impairment, which is one of the results from social exclusion and leads to logical reasoning disorders. This study also investigate how cognitive errors called abductive inference error occur due to cognitive impairment. Present study was performed with 81 college students. Participants were randomly assigned to the group who has experienced social exclusion or to the group who has not experience the social exclusion. We analyzed how the degree of error of abductive inference differs according to the social exclusion experience. The group who has experienced social exclusion showed a higher level of abductive inference error than the group who has not experience. The abductive condition inference value of the group who has experienced social exclusion was higher in the group with the deduction condition inference value of $90 \%$ than in the group with the deduction condition inference value of $10 \%$, and the difference was also significant. This study extended the concepts of cognitive impairments, escape theory, cognitive narrowing which are used to explain addiction behavior to human cognitive bias. Also this study confirmed that social exclusion experience increased cognitive impairment and abductive inference error. Future research directions and implications were discussed and suggested.
\end{abstract}

Keywords: Abductive Inference, Cognitive Impairments, Social Exclusion

JEL Classification Code: D11, D12, M31

\section{Introduction}

Abductive conditionals have not yet been investigated in the probabilistic truth table task paradigm. Abductive conditionals can be conceived as reversed causal conditionals, characterized as follows: the effect is located in the conditional's antecedent and the cause is located in the conditional's consequent. For example, if your headache disappeared, then you took aspirin. Abductive inferences are also known as inferences to the best explanation (for philosophical and psychological overviews on abduction see, e.g., Douven, 2011; Lombrozo, 2012, respectively). Like indicative and causal conditionals, abductive conditionals can be formulated in indicative and in subjunctive mood (Pfeifer \& Tulkki, 2017).

\footnotetext{
${ }^{1}$ First Author and Corresponding Author. Associate Professor, Department of Business Administration, Myongji University, Korea [Postal Address: 34, Geobukgol-ro, Seodaemun-gu, Seoul, Korea] Email:whhan@mju.ac.kr

(c) Copyright: The Author(s)

This is an Open Access article distributed under the terms of the Creative Commons Attribution Non-Commercial License (http://Creativecommons.org/licenses/by-nc/4.0/) which permits unrestricted noncommercial use, distribution, and reproduction in any medium, provided the original work is properly cited.
}

Explanatory judgments are central to abductive reasoning, that is: inferring to the available hypothesis that can best explain the evidence. Understanding what determines the explanatory power of a hypothesis is of crucial importance for researchers in different fields: for cognitive psychologists, who study the principles of human reasoning (e.g., Oaksford \& Chater, 2000); AI researchers, who use abduction for belief revision, knowledge representation and fault diagnosis; for philosophers of science and epistemologists, who investigate the rationality of abductive inferences, and their relation to probabilistic inference (Douven, 2011).

Expanding on a growing body of literature in the philosophy and cognitive psychology of explanation, we investigated (i) how explanatory power relates to other features of a hypothesis with respect to an explanation, such the hypothesis' degree of confirmation, its causal relevance, logical relations, and the sense of understanding it provides; and (ii) how probabilistic information affects explanatory judgment (Colombo, Postma, \& Sprenger, 2016). Recently, the social exclusion has increased and then more people are suffering from negative emotions and cognitive impairment from the social exclusion. Kahneman and Tversky (1973) found that the basal rate error, which is the cause of the abductive reasoning error, occurs due to the limitation 
of cognitive ability of many people, and mainly when the system 1 operates. Unlike previous studies on abductive error, this study aims to find the condition of system 1 in which abductive reasoning error occurs in cognitive impairment caused by social exclusion.

This study examines the mechanism of cognitive narrowing, which is a strategy to overcome the negative emotions from social exclusion (Han, 2020a), and how abductive inference errors occur due to cognitive narrowing. This investigation is relied upon to be valuable for the investigation of social prohibition and the subsequent buyer conduct, specifically, the mistake of customer dynamic and the organization's showcasing methodology.

\section{Literature Review}

\subsection{Abductive Reasoning}

Abduction, a term first introduced by philosopher Charles Sanders Peirce, is a unique way of inferring a cause or reason from an outcome. If deduction is to infer certain consequences, and induction is to create a valid rule until the opposite is found, then abduction can be seen as inferring a plausible but still uncertain cause. Deductive reasoning and abductive reasoning both require conditional statements, if $\mathrm{x}$ represents the cause and $y$ indicates the result, the causal term " $y$ " can be expressed in $\mathrm{p}(\mathrm{y} \mid \mathrm{x})$, which is used in deductive reasoning. On the other hand, a derivative conditional statement that "if there is a result of y" can be expressed in $p(x \mid y)$, which is used for abductive inference. It can be seen that the constitution of the conditional statements of abductive and deductive reasoning is reversed. That is, while deductive reasoning is to draw conclusions from the given evidence, abductive reasoning is the opposite of deductive reasoning in the sense that abductive reasoning should determine the probability of the hypothesis in the given evidence, as well as the conditional statements between the hypothesis and evidence (Josang, 2008). Moreover, because people generally think of deduction reasoning more naturally than abductive reasoning, they tend to make causal reasoning in most reasoning situations where abductive reasoning is required. In other words, there is a situation where abductive and deductive reasoning are often confused, which causes a base rate fallacy (Josang, 2008).

According to the representative heuristic, the probability of event $A$ being true given event $B$ is calculated based on how similar events A and B are. For example, if event A is found to be very similar to event $B$, the probability of condition in event $\mathrm{A}$ is very high when given event $\mathrm{B}$. In other words, the representative heuristic is based on the assumption that the representativeness of a category in the real world consists of the most common and important features existing among the members of the category (Nilsson, Olsson, \& Juslin, 2005).
Representative heuristics often lead to accurate and useful predictions, but they also risk overlooking important things if you become overly dependent on them. One thing that may be overlooked is the prior probability or base rate of the result. No matter how many new products are similar to successful ones, the new products can still fail if the industry itself has a very low success rate (Kardes, Cronley, \& Cline, 2008).

Therefore, base rate error or base rate neglect is a logical error that occurs when probabilistic judgment is made by using inappropriate information while ignoring the empirical statistics called prior probability or base rate. Kahneman and Tversky (1973) analyzed the basal rate error in a systematic experiment and found that the basal rate error is due to representative heuristics. In other words, basal rate errors were viewed as a reflection of their dependence on representative heuristics (Evans, Simon, David, \& Perham, 2002).

As we saw earlier, the base rate error occurs in the process of evaluating the conditional probability of $y$ given some evidence $\mathrm{x}$ without considering the base rate for the hypothesis $y$. That is, the base rate error results from the incorrect assumption that $\mathrm{p}(\mathrm{y} \mid \mathrm{x})$ is equal to $\mathrm{p}(\mathrm{x} \mid \mathrm{y})$ (Josang $\&$ O'Hara 2010). In other words, many people fall into the inverse error that confuses causal and derivative conditions, which makes it difficult to make accurate inferences and judgments about the cause even when it is necessary for inferential reasoning. This error of abductive inference can be supposed to occur in cognitive impairment and cognitive narrowing where the cognitive working range is consciously and unconsciously reduced. Cognitive narrowing can result in false attribution and lack of causal thinking, leading to abductive inference errors.

\subsection{Cognitive Impairment}

Social rejection alludes to the procedure by which people are blocked from different rights, openings, and assets that are commonly accessible to individuals from different gatherings and are basic for social coordination and human rights consistency inside specific gatherings (Silver, 1994). There are clashing investigations on how individuals who have encountered social avoidance respond. As per the hypothesis of the social observing framework, social prohibition additionally makes it hard for people to have a place with a gathering and along these lines spur people to discover social pieces of information that can be remembered for the gathering once more (Pickett and Gardner 2005). In this way, they are keen on making new wellsprings of social relations (Maner, Dewall, Baumeister, \& Schaller, 2007), or are extremely delicate to social acknowledgment (DeWall, Maner, \& Rouby, 2009), and expend more items representing 
bunch enrollment (Mead, Baumester, Stilman, Rawn, \& Vohs, 2011).

Then again, social prohibition can increment standoffish conduct, which is something contrary to seeking after consistence. The individuals who have encountered social avoidance are increasingly forceful (Buckley, Winkel, $\&$ Leary, 2004), and are less inclined to contribute and coordinate less with others (Twenge, Baumeister, Dewall, Ciarocco, \& Bartels, 2007). It has additionally been appeared to decrease prosocial conduct and lead to an expansion in foolish conduct (Twenge, Catanese, \& Baumeister, 2002). The individuals who experience dismissal show increasingly introverted conduct and less eagerness to perform charitable and generous practices, for example, helping other people, all of which include self-guideline disappointment.

Exactly when people locate the opportunity of social disallowance, they may have the alternative to cover their energetic responses, which will hold onto human selfregulatory systems. In case the advantages of oneself are totally used to cover emotions, they won't be adequate to control the abstract system. In this way, logically customized scholarly systems can be worked commonly immaculate, yet controlled techniques can be difficult to work. Toward the day's end, social dismissal corners a bit of the advantage of the self-execution work, explicitly subverting the controlled system. Unavoidably, they will have less impact on for the most part customized (less capable and less controlled) assignments, yet mischief can be found in tasks that require dynamic theory, for instance, thinking and method of reasoning.

The Escape Model relies upon the speculation of differentiating the ideal self and the certified self and has been applied to represent wild practices, for instance, unquenchably expending food and implosion (Heatherton \& Baumeister, 1991). As it were, the escape model is a hypothetical system that sees how individuals can escape from their disdainful and negative passionate states. One way to deal with diminish negative sentiments is to diminish care, making the irregularity among self and related measures not, now verbalized (Duval \& Wicklund, 1972). This diminishing of care, cognitive narrowing, is one of the significant sorts of excursions considered to escape models.

By virtue of cognitive narrowing, the point of convergence of thought is restricted by focusing just on current musings close enough, express and low-level considerations, and declining to think broadly and really (Baumeister, 1990). As it were, proof of cognitive narrowing or psychological disintegration may incorporate solid considerations, quick objectives, and subjective unbending nature. Specifically, there are many highly contrasting rationales that are normal for subjective unbending nature. Yet, escape from these negative feelings likewise triggers various reckless practices, for example, pigging out, and endeavors to get away from upsetting feelings through intellectual narrowing can bring about disturbing the typical limitation related with food and submitting unreasonable reasoning (Han, 2020b, 2020c, 2020d). The more people maintain a distance from significant reasoning, the more they are to be objective and less basic, and certain they are not to discover any convictions or ends.

At the point when an individual is hesitant to think definitively, it gets wasteful to fundamentally assess new thoughts when contrasted with regular circumstances. A few distortion of cognition in gorge eaters, including broken attributions, personalization, amplification, dichotomous reasoning, sifting, overgeneralization, and enchanted reasoning (Johnson, Connors, \& Tobin, 1987, Han 2020a). Cognitive narrowing in like manner shields us from thinking about the drawn-out importance of explicit practices, for example, causal reasoning (Faver, 2004, Han, 2020a).

While cognitive impairment refers to time distortion, lethargic passivity, and avoidance of self-awareness caused by social exclusion, cognitive narrowing means focusing only on low-level phenomena by reducing the range of attention to avoid negative emotions. Both are common in avoiding or reducing self-awareness, but cognitive impairment is broader than cognitive narrowing in cause and phenomenon (Han, 2020a). Among them, the fake attribution and the nonappearance of causal thinking are particularly undeniable, which is related to the abduction error. Namely, the false attribution caused by cognitive impairment can lead to error of abductive inference. In this study, the following hypothesis is established.

Hypothesis: Group who have experienced social exclusion will show a higher degree of abductive inference errors than those who have not.

\section{Research Methods}

This research was performed with 81 understudies in Seoul. Subjects were randomly appointed to the cluster who encountered social prohibition and the cluster who didn't experience social avoidance. We investigate how the level of abductive inference error varies as social exclusion experience. The control of social rejection experiences has employed situation manipulation techniques for enrollment for membership (Wan, Xu, \& Ding, 2014). Members were given a story and inquired to examined it carefully and emphasized the significance of getting into the character's part and feelings whereas perusing the story as in case within the same occasion in genuine life. The scenario appears that most character planning for business is energetic to connect 'SUCCESS', a work arrangement club that gives strong data and successful learning methodologies and boasts high work victory rates. It contains that the most character has applied a membership form to the work planning club 'SUCCESS'. 
Under social avoidance, the most character was reached by the club many days afterward that his application was denied. And beneath social consideration, the most character was educated that the application was affirmed.

Next, participants had been asked to reply to manipulation take a look at query about emotions of exclusion or neglect whilst describing the experience $(1=$ strongly disagree, $7=$ strongly agree). The survey booklet presented participants with an assignment associated with abductive inference and requested to resolve. Abductive inference reasoning was measured by the following procedure. Participants were requested to read the following scenario.

"In September, the Korea Consumer Protection Agency surveyed electronics stores in downtown Seoul and found that wireless earphones sold at electronics stores differed significantly in quality and price. In general, the quality of wireless earphones depends on their performance and weight. According to the Consumer Protection Survey, when purchasing a high-end wireless earphone, the probability of the price being 100,000 won is about 90 percent. And when you buy wireless earphones that are not of the highest quality, the probability of the price being 100,000 won is about $8 \%$."

The data suggest probabilities for 'deductive condition inference'. In other words, the probability that the price is 100,000 won when purchasing high-end wireless earphones (= P (100,000 won| high-end wireless earphones)) and the probability that the price is 100,000 won when purchasing non-high-end wireless earphones $(=\mathrm{P}(100,000) \mid$ highend wireless earphones) are presented in sentence format expressed as \%. Deductive condition inference consisted of '90\% 'and ' $10 \%$ ' and subjects were assigned to one of the two levels randomly. Subjects who had read the above data were asked the following questions about inferential condition inference.

When you purchased a 100,000 won wireless earphone at an electronics store in Seoul, what is the probability that the wireless earphone is of high quality?

In other words, if you purchased a wireless earphone for 100,000 won, what is the probability that the wireless earphone is a high-end wireless earphone? ( $=\mathrm{P}$ (high-end wireless earphone|100,000 won)). Answers to the question of "abductive inference" were required to mark on the choices in $10 \%$ increments, from $0 \%$ to $100 \%$.

Inverse error means to confuse conditional probability with its inverse probability. This can be said to be influenced by deductive condition reasoning in the situation where abductive conditional reasoning is needed by confusing the value of abductive reasoning and deduction reasoning. Therefore, if all other conditions are the same, if the value of the abductive inference required by the task differs according to the presented deductive condition inference, and the difference in the value is statistically significant, it can be considered that the inverse error has produced that is affected by the deductive condition reasoning. Since the base rate information is not presented in this study, various threshold condition probability values can be presented as answers depending on how the subjects estimate the base rate value. However, if the value of deductive conditional reasoning is $10 \%$ and $90 \%$, respectively, $\mathrm{M} 10 \%$ and $\mathrm{M} 90 \%$, then (1) indicates the relationship of $\mathrm{M} 10 \%<\mathrm{M} 90 \%$ (2) and the difference between these values is significant, the abductive condition inference value is influenced by the deductive condition inference value and can be interpreted as an inverse error occurrence. On the other hand, if M10\% and M90\% do not have the above relationship or the difference is not significant, it can be said that inverse error has not occurred.

\section{Research Results}

Participants' responses to the manipulation check questionnaire were averaged (Wan, Xu, \& Ding, 2014). Participants under rejected (vs. accepted) condition felt more excluded $(\mathrm{M}=4.74$ vs. $\mathrm{M}=2.05 ; t(79)=-15.039, \mathrm{p}<.001)$, indicating the success of the manipulation. According to the analysis of the abductive inference, in the social exclusion experience group, it was shown that there was an abductive inference error, but in the social exclusion non-experience group, there was no abductive inference error.

In other words, as can be seen in $<$ Figure $1>$, in the social exclusion non-experience group, the abductive condition inference value was turned out to be higher in the group with the deductive condition inference value of $90 \%$ than in the group with the deductive condition inference value of $10 \%$, but the difference was not significant $\left(\mathrm{M}_{10 \%}=44.67 \mathrm{vs}\right.$ $\left.\mathrm{M}_{90 \%}=49.26 ; t(40)=-0.742 \mathrm{p}>.1\right)$.

On the other hand, as can be seen in $\langle$ Figure $2>$, the abductive condition inference value of the social exclusion feeling group was higher in the group with the deduction condition inference value of $90 \%$ than in the group with the deduction condition inference value of $10 \%$, and the difference was also significant $\left(\mathrm{M}_{10 \%}=30.40\right.$ vs $\mathrm{M}_{90 \%}=47.86$; $t(37)=-2.031, \mathrm{p}<.05)$. Therefore, the hypothesis that groups experienced social exclusion were anticipated to show a higher degree of abductive inference error than those who did not have social exclusion experience was supported.

\section{Conclusions}

This examination found that the occurrence of mistake of abductive derivation in the gathering that accomplished social prohibition was higher than that in the gathering that didn't encounter social rejection. Numerous studies that specialize in these irrational aspects of shoppers have varied opinions on the origins and characteristics of irrational choices and judgments. According to the views that the 


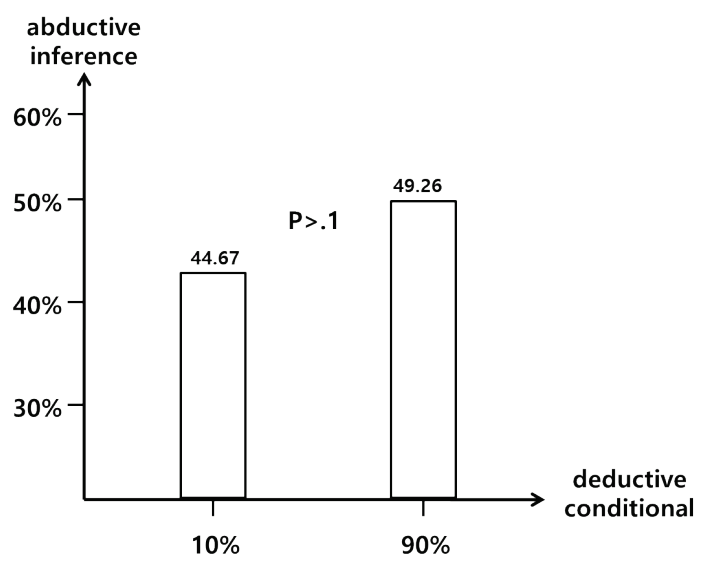

Figure 1: Social Inclusion and Abductive Inference

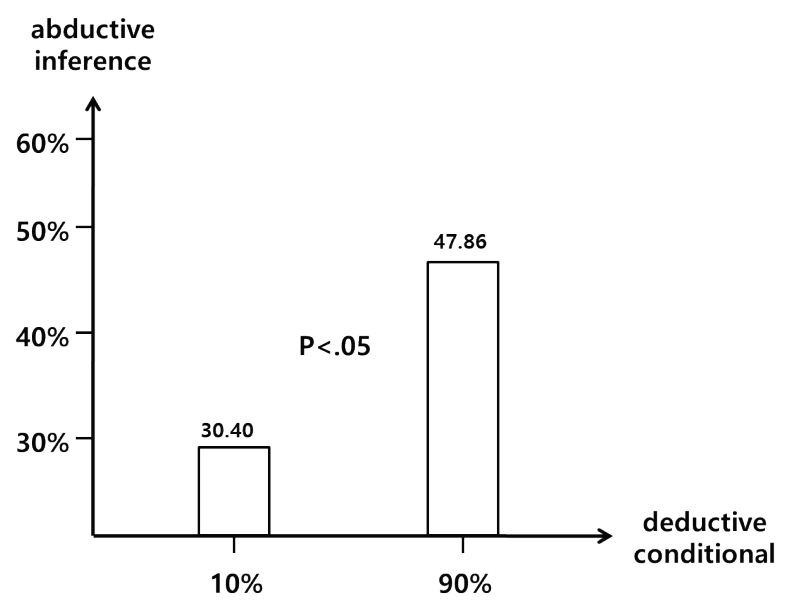

Figure 2: Social Exclusion and Abductive Inference

irrational behavior of consumers appears to be as a result of the deep-rooted limitations of human cognition (Kahneman \& Frederic, 2002; Kahneman \& Tversky, 1982), that human efforts to make rational decision-making and judgments usually biased by reason of human cognitive limitations. Dual process model explains in the event that System 1 of the two virtual cerebrums or brains of people is initiated, people are bound to fall into psychological blunder. This model is known to frame the premise on which System 1 can work contingent upon the idea of the undertaking to be processed, and the encouragement of the individual taking care of the task.

Unlike previous studies on abductive reasoning, this study confirmed that cognitive impairment from social exclusion can lead to defects in logical reasoning. In this research, it was expected that cognitive error occurs when
System 1 operates because cognitive narrowing strategy is adopted to overcome one's social exclusion experiences and emotions from the experiences. Especially, current research focused on the exclusion experience and the cognitive response strategy under which System 1 operates. Past examinations have concentrated distinctly on the way that the negative feelings of consumers can cause intellectual narrowing, and this subjective narrowing realizes different psychological blunders or psychological biases.

This investigation was proposed to foresee and recognize the part by which errors or inclination would be in the activation of System 1. The results of this study indicates that if the social rejection experience brings about subjective narrowing and this results in psychological errors by the functioning of System 1, the event of different intellectual inclinations along with the blunder of inference thinking, cognitive errors.

This study has the theoretical implications as follows. First, it extends the idea of imprecise self-awareness, cognitive rigidity, and escape model to analyze addictive behavior like impulsive consumption to cognitive mistakes. Next, it clarified the structure of social exclusion by cognitive narrowing model and dual process model.

In practice, consumers with social exclusion experience cannot infer the exact cause due to abductive inference error. In this case, a marketing communication strategy can be considered to provide consumers with a definite basis for the results by providing deductive condition inferences that emphasize only the results from one cause, without mentioning the other causes that may result. Social inclusion is an important for the health and welfare both of individual and the entire society. Hence various efforts are required to reduce social exclusion and rejection in order to maintain rational and sound consumer activities and a healthy social community.

This research has some limitations. Because the participants were recruited only from undergraduate students, it is required to interpret carefully the result of this study and future research need to recruit consumers of various ages and occupations. Future research need to compare various social exclusion related variables. Finally, current research examined only the influence of social exclusion and cognitive narrowing on abductive inference error. Future research need to explore the mechanism of various types of cognitive errors.

\section{References}

Baumeister, R. F. (1990). Anxiety and deconstruction: On escaping the self. In: J. M. Olson, \& M. P. Zanna (Eds.), Ontario Symposium on Personality and Social Psychology. SelfInference Processes: The Ontario Symposium, 6 (pp. 259-291). Mahwah, NJ: Lawrence Erlbaum Associate, Inc. 
Buckley, K., Winkel, R., \& Leary, M. (2004). Reactions to acceptance and rejection: Effects of level and sequence of relational evaluation. Journal of Experimental Social Psychology, 40(1), 14-28.

Colombo, M., Postma, M., \& Sprenger, J. (2016). Explanatory judgment, probability, and abductive inference. In: A. Papafragou, D. Grodner, D. Mirman, \& J. C. Trueswell (Eds.), Proceedings of the 38th Annual Conference of The Cognitive Science Society (pp.432-437). Austin, TX: Cognitive Science Society.

DeWall, N. C., Maner, J. K., \& Rouby, A. D. (2009). Social exclusion and early-stage interpersonal perception: Selective attention to signs of acceptance. Journal of Personality and Social Psychology, 96(4), 729-741.

Douven, I. (2011). Abduction. In: Edward N. Zalta (ed.), The Stanford Encyclopedia of Philosophy (Spring 2011 Edition). Standford, CA: Stanford University.

Duval, S., \& Wicklund, R. A. (1972). A theory of objective selfawareness. San Diego, CA: Academic Press.

Evans, J. S. B. T., Simon, J. H., David, E. O., \& Perham, N. (2002). Background beliefs in Bayesian inference. Memory and Cognition, 30(2), 179-190.

Faver, R. J. (2004). Self-control and compulsive buying. In: T. Kasser, \& A. D. Kanner (Eds.), Psychology and consumer culture: The struggle for a good life in a materialistic world (pp. 169-187). Washington, DC: The American Psychological Association.

Heatherton, T. F., \& Baumeister, R. F. (1991). Binge eating as escape from self-awareness. Psychological Bulletin, 110(1), 86-108.

Johnson, C., \& Connors, M. E., \& Tobin, D. L. (1987). Symptom management of bulimia. Journal of Consulting and Clinical Psychology, 55(5), 668-676.

Josang, A. (2008). Conditional reasoning with subjective logic. Journal of Multiple-Valued Logic and Soft Computing, 15(1), $5-38$.

Josang, A., \& O'Hara, S. (2010). The base rate fallacy in belief reasoning. Proceedings of the 13th International Conference on Information Fusion (FUSION 2010), Edinburgh, Scotland.

Han, W. H. (2020a). Does social exclusion influence consumers' pseudodiagnosticity biases towards distribution brands? Journal of Distribution Science, 18(4), 79-85.

Han, W. H. (2020b). Impulsive buying and social exclusion. Journal of Product Research, 38(3), 53-59.

Han, W. H. (2020c). The study on compulsive buying as selfdefeating behavior: Focused on social exclusion factor. East Asian Journal of Business Economics, 8(2), 57-68.

Han, W. H. (2020d). How consumers' mindfulness moderates impulsive buying tendency. Services Marketing Journal, 13(1), 5-17.

Kahnemann, D., \& Frederick, S. (2002). Representativeness revisited: Attribute substitution in intuitive judgment. In:
T. Gilovich \& D. Griffin (Eds.), Heuristics and biases: The psychology of intuitive judgment (pp. 49-81). New York, NY: Cambridge University Press.

Kahneman, D., \& Tversky, A. (1973). On the psychology of prediction. Psychological Review, 80(4), 237-251.

Kahnemann, D., \& Tversky, A. (1982), Judgment under uncertainty: Heuristics and biases. New York, NY: Cambridge University Press.

Kardes, F. R., Cronley, M., \& Cline, T. (2008). Consumer behavior. Mason, OH: South-Western Cengage Learning.

Lombrozo, T. (2012). Explanation and abductive inference. In: K. J. Holyoak \& R. G. Morrison (Eds.), The Oxford handbook of thinking and reasoning (pp.260-276). Oxford, UK: Oxford University Press.

Maner, J. K., DeWall, N. C., Baumeister, R. F., \& Schaller, M. (2007). Does social exclusion motivate interpersonal reconnection? Resolving the 'porcupine problem. Journal of Personality and Social Psychology, 92(1), 42-55.

Mead, N. L., Baumeister, R. F., Stillman, T. F., Rawn, C. D., \& Vohs, K. D. (2011). Social exclusion causes people to spend and consume strategically in the service of affiliation. Journal of Consumer Research, 37(5), 902-919.

Nilsson, H., Olsson, H., \& Juslin, P. (2005). The cognitive substrate of subjective probability. Journal of Experimental Psychology: Learning, Memory, and Cognition, 31(4), 600-620.

Oaksford, M., \& Chater, N. (2000). Bayesian rationality. Oxford, UK: Oxford University Press.

Pfeifer, N., \& Tulkki, L. (2017). Abductive, causal, and counterfactual conditionals under incomplete probabilistic knowledge. 39th Annual Meeting of the Cognitive Science Society (COGSCI 2017), 26-29 July 2017, London, UK.

Pickett, C. L., \& Gardner, W. L. (2005). The social monitoring system: Enhanced sensitivity to social cues as an adaptive response to social exclusion. In: Williams, K. D., Forgas, J. P., \& Hippel, W. V. (Eds.), Sydney Symposium of Social Psychology series. The Social outcast: Ostracism, social exclusion, rejection, and bullying (pp.213-226). New York, NY: Psychology Press.

Silver, H. (1994). Social exclusion and social solidarity: Three paradigms. International Labour Review. 133(5), 531-578.

Twenge, J. M., Baumeister, R. F., Dewall, N. C., Ciarocco, N. J., \& Bartels M. J. (2007). Social exclusion decreases prosocial behavior. Journal of Personality and Social Psychology, 92(1), 55-66.

Twenge, J. M., Catanese, K. R., \& Baumeister, R. F. (2002). Social exclusion causes self-defeating behavior. Journal of Personality and Social Psychology, 83(3), 606-615.

Wan, E. C., Xu, J., \& Ding, Y. (2014). To be or not to be unique? The effect of social exclusion on consumer choice. Journal of Consumer Research, 40(6), 1109-1122. 